\title{
Vincent Luciani Responds
}

To the Editor:

Yes, I had read "Amazing Grace" (Ring, 1991) rather carefully, and in fact had read one of its accounts, that of a near-death experiencer (NDEr) friend, perhaps even before Kenneth Ring had. Nor am I the only bona fide NDEr in disagreement with Ring's inappropriate conclusion that those four - or any 4,000-NDE narratives could tell us all there was to be told about any aspect of near-death, most especially its aftereffects.

Perhaps it was $m y$ letters (Luciani, 1992, 1993) that were not understood. What I had suggested was that some NDErs have had it with those who extract only the glamorous near-death visions from experiencers, and then step back when the nitty-gritty aftereffects come up for study.

It bothers me that Ring cavalierly announces, almost as an afterthought, "maybe I'll even gather together a bunch of essays on NDEs and bring them out as a book!" I've spent most of my career as a project manager on many systems encompassing the entire dynamic test cycle from hypothesis to statistical analysis and reporting, and I was very good at what I did - good enough to have earned the right to say I simply don't classify as scholarly research the gathering together of a bunch of essays to bring out a book. In point of fact, it is precisely contrary to everything I've been trying to say in these pages about doing solid research on post-NDE responses.

And so I hereby say one last time - and I challenge anyone to refute this - that every NDEr receives a spiritual mandate at the time of near-death, whether remembered afterward or not, to do something substantially different with their reprieved lives. It had been my hope that through properly conducted research into the afterlives of NDErs, sincerely motivated researchers might one day report conclusive evidence in support of this contention, thereby saving many NDErs, present and future, quite unnecessary anguish.

To Ring, Raymond Moody, Melvin Morse, and other authors: that's the only new book from any of you I'd care to read.

\section{References}

Luciani, V. (1992). Kenneth Ring's swan song [Letter]. Journal of Near-Death Studies, $11,64-67$. 
Luciani, V. (1993) . A new life for near-death studies [Letter]. Journal of Near.Death Studies, 112, 67-68.

Ring, K. (1991). Amazing grace: The near-death experience as a compensatory gift. Journal of Near.Death Studies, 10, 11-39.

Vincent Luciani

44725 East Florida Avenue, Sp. 36

Hemet, CA 92544 